This instrument, in favourable circumstances of weather, will measure ranges in a few seconds of time with an accuracy of something like 3 yards at 1000 yards, 30 at 3000 , I 20 at 6000 , and so on. Prof. Barr, of the University of Glasgow, and the lecturer devised the instrument in its main features in 1888 ; it took, however, a period of five years to make a satisfactory naval instrument, and for the past seven years the improvement of the optical and mechanical details has been going on. ${ }^{1}$

Fig. 3 shows the same instrument mounted for fortress observation.

It is claimed for these instruments that they offer a solution -of course not necessarily the only or the best-of the problem of range-finding in all cases where want of portability is not a drawback.

$B$. and S. Field Range-finder.-Fig. 4 shows a smaller instrument of the same type with a base of 3 feet, which weighs 12 lbs. One of these instruments has been used by Major Guinness in South Africa since the beginning of February, and that officer reports that after carrying the instrument on his ammunition wagon over all sorts of ground for six months it was in no way damaged or deranged. The figure shows how

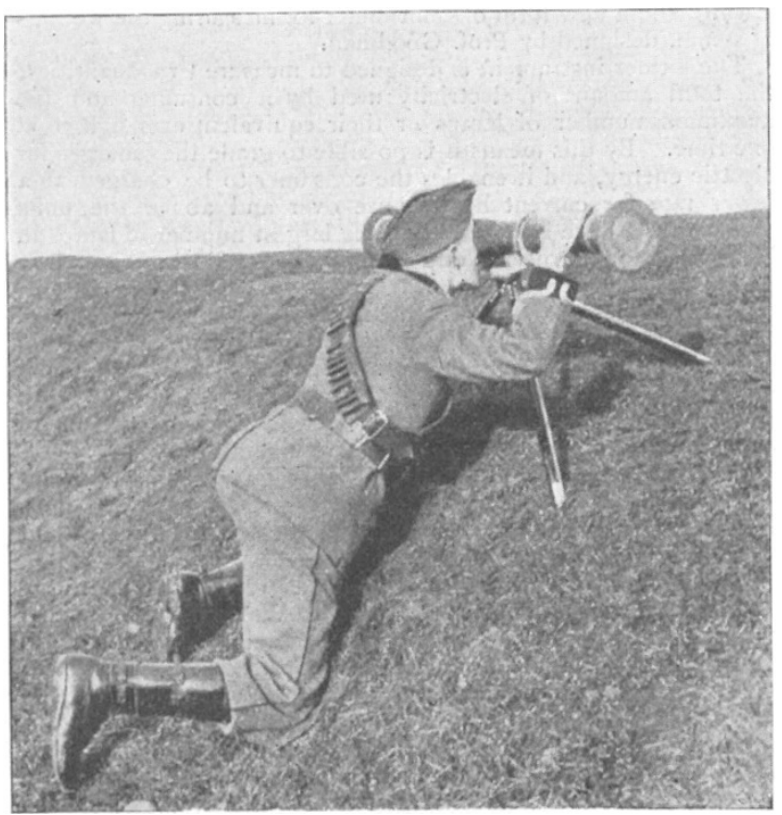

Fig. 4.-Barr and Stroud field range-finder.

the range-finder can be used for taking a distance with practically no exposure of the man.

The lecturer concluded by describing and exhibiting the electrical telegraph for naval use which Prof. Barr and he had devised at the request of the Admiralty, so as to enable the captain of the ship in the conning tower to receive from the range-taker continuous records of the ememy's distance and to transmit the same and also orders to the guns. The importance of trustworthy means for transmitting orders and other communications from one station to another on a warship is now fully realised. Thus, for example, it is reported that in the opinion of Adnirals Fournier and de Beaumont and the officer in command, the loss of the French torpedo-boat destroyer Fritmee, which occurred about a month ago, was due to the fact that the apparatus on board the vessel for the transmission of ordérs was inadequate. The need for continuous and almost irstantaneous transmission of ranges to the gunners will be obvious when it is remembered that in naval engagements the range is continually and rapidly altering.

The lecturer concluded by expressing his thanks to Mr. J. J. Hicks, of London, Mr. Steward, of London, and Messrs, Zeiss, of Jena, for the loan of range-finders to illustrate the lecture.

1 Readers unacquainted with the instrument are referred for details of its construction to Transactions of Inct. of Mech. Eng. (1806), or Engizecring, 1896 Part i. p. 233 , \&c.

NO. 1616 , VOL. 62]

\section{MECHANICS AT THE BRITISH ASSOCIATION}

A LTHOUGII no very striking paper was presented to the section at this meeting, still several papers of value and of considerable interest were dealt with.

In the committee of the section two very important pieces of work were carried out. The committee on small screw gauges, which has now been at work for some years, presented an interim report in which the difficulties the committee had met with in obtaining standard gauges were very fully discussed, and an account of some experiments on different forms of threads, made by Mr. T. M. Gorham and Mr. W. A. Price in the laboratory of Prof. Hudson Beare at University College, London, were described. The committee stated in their report that they have now every hope of bringing their inquiry to a successful conclusion, and the committee was therefore reappointed and a grant was secured for the necessary expense of completing the work.

A committee was also appointed at Bradford to deal with the question of the resistance of road vehicles to traction. Prof. Hele Shaw read a short paper before the section, drawing attention to the need of modern experiments on the nature of the resistances encountered by vehicles on the common road. He pointed out how the growth of the cycle and motor car industry made information upon this point a matter of the greatest importance.

There is no doulst that we are on the eve of a very considerable increase in mechanical propulsion on common roads, and at present designers of such vehicles have to rely largely upon old experiments with solid steel tyres, and carried out on roads very different indeed from the modern roads. The powerful auto cars which can now be obtained make it comparatively an easy matter to determine the tractive power necessary to move a vehicle with any load upon any type of road, and no doubt the work of the committee will largely consist-after a suitable dynamometer and speed indicator have been arranged for-in carrying out exhaustive experiments with different types of vehicles and different types of tyres on all the various classes of roads now in use.

A grant of money was secured from the Association for the purposes of this committee, and we have every hope that when the committee submits its report it will justify its appointment.

In the work of the section papers by local engineers bulked largely. Perhaps the two most interesting and valuable were a paper by Mr. J. Watson, the Waterworks engineer at Brad ford, in which the new Nidd Valley Waterworks were de scribed, and the paper by Mr. J. MacTaggart, the Superintendent of the Cleansing Department of the City of Bradford, entitled "The Disposal of House Refuse in Bradford."

In Mr. Watson's paper a short historical summary of the various schemes for supplying Bradford with water was given, followed by a very exhaustive and complete account of the Nidd Valley scheme. This scheme, now rapidly approaching completion, is one which will cost the City of Bradford nearly I, 500,000/. and will afford a supply of about twenty million gallons of water per day, and in addition will provide a large compensation reservoir (Gouthwaite) for the land-owners along the Nidd Valley.

It is essential for such a city as Bradford, where the chief industry is that of the woollen trade, that the water shall be very soft, and, of course, this led to some difficulty in finding a suitable collecting ground for the city supply.

The section had the opportunity of visiting, under the guidance of Mr. Watson, portions of the works on the Saturday of the meeting.

In I Mr. MacTaggart's paper very valuable information was given as to the most modern methods in a big manufacturing city for the disposal of the daily city refuse. So successful have the various arrangements been, mostly due to the author, that it is hoped in time the destruction of the whole of the refuse of the city will be carried out, not only without creating any nuisance, but without any cost to the ratepayers. The refuse is chiefly dealt with by destructors, and the great merit of the Bradford sysiem is in the utilisation of the clinker produced in the destructor furnaces for various useful purposes, the power to work the machinery required for these purposes, and the lighting of the works all being obtained from the steam generated by the surplus heat of the destructors. A large number of specimens were shown to the section of concrete paving-slabs, 
bricks and encaustic tiles manufactured from the clinker, and some interesting figures as to the strength of these materials were also given.

Another paper by a Yorkshire engineer, Mr. E. K. Clark, dealt with the subject of the shop buildings in large engineering works. The author had collected a large amount of statistics and figures, both as to the method of construction now generally adopted-viz., the shops all on one level-and as to the materials commonly used in their construction, and the paper will form a very valuable reference for any engineer engaged either in laying out new engineering workshops, or in reconstructing old buildings.

Mr. Glass contributed a lengthy paper dealing with the coal and iron ore fields of Shansi and Honan, and railway construction in China. The author was engaged in 1898 by a syndicate to proceed to China, and to examine and make a complete report on the coal and iron-ore fields of these two important provinces of China, and also to make surveys for the railways which it would be necessary to construct in order to utilise these deposits.

An interesting description was given of the general features of the country, illustrated by some beautiful lantern slides from photographs taken by the author, and also a very complete account of the Chinese method of working these mineral deposits. The author stated that it was somewhat difficult to arrive at very exact estimates of the quantity of coal available in these great fields, but it is believed there are more than 33,000 square miles of coal-fields in Shansi alone, and that the present output of Great Britain, which is more than 200 million tons a year, could be maintained from the anthracite coal-fields of Eastern Shansi alone for a period of 3000 years.

Samples of the coal have been analysed and show that it is a good steam coal.

Similar favourable accounts were given in regard to the iron ore deposits, and the author computed that it would be possible to produce a ton of pig-iron from these ores at the very low cost of $12 s$. I $\frac{1}{2} \mathrm{~d}$. per ton, assuming labour to be at the same rate as it is now at Middlesbrough in England. The lowest price at which the pig-iron was being sold at the foundries visited by the author was a little over 20s. per ton.

The extraordinary richness of these mineral deposits and the enormous area awaiting development show how pressing the problem of renrganising peacefully the internal government of China is for the civilised world.

On the day devoted to electrical engineering, two short communications were read by Sir Wm. Preece and Mr. F. J. Behr, dealing with the proposed Monorail High Speed Electric Line between Manchester and Liverpool.

It will be remembered this scheme came before Parliament last session and was rejected, largely owing to the strenuous ofposition of the existing railways.

The interesting feature in these papers was the account given of the brakes and signals which it is proposed to adopt, which must be an important matter on a line where it is proposed to run the trains at frequent intervals, and at such an excessiveiy high speed as I Io miles per hour. Perhaps if the promoters had been content to reduce the proposed speed somewhat at the beginning, their scheme might have been more favourably considered.

A valuable paper dealt with on this day was one on the measurement of the tractive force, resistance and acceleration of trains, by Mr. A. Mallock. The author described the apparatus which he used for the purpose, and gave an account of some experiments which he has recently carried out on these important questions. He concluded from his results that pendulum observations combined with a record of speed and power offer a simple and effective means of determining the resistance to and efficiency of electric or other kinds of motor vehicles.

On this day also, a communication from Mr. W. T. E. Binnie, a son of the president, was read, describing a new form of selfregistering rain-gauge which he has invented. The accuracy of the gauge depends on the fact that all drops falling from a tube are of constant size, provided that the tube is either very small so that the water passing down the interior chokes the bore, or that some special device is provided to spread out the water so as to wet the entire circumference of the tube. If, therefore, the weight of each drop were ascertained, it is clear that a measure of the amount of water passing down the tube would be obtained by counting the number of drops, and the electrical appliances are concerned with this part of the work.
An instrument made on this principle has been in operation for some time, and the records obtained from it in a period of five months give a total excess of $I^{\circ} 6$ per cent. over the register of an ordinary rain-gauge.

Mr. W. Dawson contributed a paper descriptive of the Demerbe system of tramway construction, a system which has been tried on the Bradford Corporation tramways and found very successful in the reduction of the cost of permanent way repairs. In the Demerbe system the rail consists of a hollow trough and the fish plate is placed inside under the ends of the rails and exactly fits its contour, the fish-plate being forced into close contact with the under side of the rail by driving in two cotters. The rail, when laid in position, is completely filled, by means of specially-designed tools, with concrete. The tie bars are flat and very simply arranged, and the gauging of the rails can, therefore, be done rapidly with almost mathematical exactitude.

The system certainly seems to have considerable merits compared to the girder system of tram rails.

Two other instruments described in short communications were a combination integrating wattmeter and maximum demand indicator, the invention of Mr. J. H. Barker and Prof. Ewing, and a new form of calorimeter for measuring the wetness of steam, designed by Prof. Goodman.

The former instrument is designed to measure two quantities, the total amount of electricity used by a consumer and the maximum number of lamps or their equivalent ever lighted at one time. By this means it is possible to grade the charges for electric energy, and it enables the consumer to be charged at a lower rate for current he may use over and above the units which would have been used had the largest number of lamps in his installation burnt for one hour every day during the whole period the current was in use.

Prof. Goodman's instrument is intended to get over some of the more serious difficulties in measuring the wetness of steam supplied by any boiler. He discards entirely the wire-drawing system, and determines the wetness by condensing a known weight of the mixed steam and water in a known weight of cold water, and measuring the rise of temperature.

Prof. Beaumont, of Leeds, in a most interesting paper described the photographic method of preparing textile designs due to Szczepanik, a number of designs being shown which had been produced by this process.

In continuation of a paper which was read before the Association at Liverpool in I896, Mr. A. T. Walmisley gave further information as to the use of expanded metal in concrete work, and gave particulars of a number of important tests which have been carried out to determine the increase of strength and the adhesion between the concrete and the metal.

The attendance at the sectional meetings was very good, and the president, Sir Alexander Binnie, may be congratulated on a successful and useful meeting.

BOTANY AT THE BRITISH ASSOCIATION.

$\mathrm{N}$ the absence of Prof. Vines the presidential address was read by Dr. D. H. Scott. On the motion of Prof. Bayley Balfour, supported by Prof. Marshall Ward, Prof. Bower and other speakers, it was unanimously agreed to ask the Recorder of the Section to convey to Prof. Vines the sincere regret of the Botanists that he was prevented by illness from presiding over their meeting.

The customary semi-popular lecture was this year delivered by Prof. Percy Groom, who chose for his subject " Plant-form in relation to nutrition."

On Monday, September Io, the Section of Geology joined Section $\mathrm{K}$ in a discussion on the conditions under which the plants of the Coal Period grew. The discussion was opened by Mr. Kidston (Stirling), who gave a general account of the flora of the Coal-measures, illustrated by a series of excellent photographs of the various types of Upper Carboniferous plants. $\mathrm{Mr}$. Seward dealt with the botanical evidence bearing on the climatic and other physical conditions under which coal was formed. On the geological side the discussion was opened by Mr. Strahan and Mr. Marr. Dr. Horace Brown discussed the question of the possible richness in $\mathrm{CO}_{2}$ of the coal period atmosphere, and gave an account of some of his recent experiments with plants grown in an atmosphere containing twice or thrice the present amount of carbonic acid gas. Dr. Scott, Dr. Blackman, and Prof. Hartog also took part in the discussion from the botanical standpoint.

No. 1616 , voL. 62$]$ 